\title{
Evidence-Based Physiotherapy Culture-The Influence of Health Care Leaders in Sweden
}

\author{
Petra Dannapfel, Per Nilsen \\ Department of Medicine and Health, Linköping University, Linköping, Sweden \\ Email: petra.dannapfel@liu.se
}

How to cite this paper: Dannapfel, P., \& Nilsen, P. (2016). Evidence-Based Physiotherapy Culture-The Influence of Health Care Leaders in Sweden. Open Journal of Leadership, 5, 5169. http://dx.doi.org/10.4236/ojl.2016.53006

Received: April 25, 2016

Accepted: August 13, 2016

Published: August 16, 2016

Copyright $\odot 2016$ by authors and Scientific Research Publishing Inc. This work is licensed under the Creative Commons Attribution International License (CC BY 4.0).

http://creativecommons.org/licenses/by/4.0/ (c) (i) Open Access

\begin{abstract}
Research in physiotherapy has increased rapidly over the last decade, yet studies have shown that many practice decisions continue to be based on knowledge obtained during initial physiotherapy education and/or personal experience, rather than findings from research. Both barriers and facilitators to achieving a more evidence-based practice (EBP) in physiotherapy have been identified. Leadership is a facilitator that has been recognized to have an important influence on the implementation of EBP in various settings. Our aim was to explore how physiotherapy leaders in Sweden influence the culture for implementation of evidence-based physiotherapy practice. Nine interviews with managers of physiotherapy clinics were conducted in various settings in Sweden. Data were analysed using qualitative analysis and a framework developed by Schein (Schein, 2010). Organizational Culture and Leadership (4th ed.). San Francisco, CA: Jossey-Bass) was applied. The framework identifies a number of mechanisms by which leaders can influence the culture of an organization and/or groups within an organization. The mechanisms of paying attention to, measuring and controlling on a regular basis as well as deliberate role modelling, teaching and coaching did have some relevance. However, EBP issues seemed to depend on committed individuals, often younger physiotherapists, who were interested in research. Overall, there was limited relevance for most of the embedding mechanisms. The findings suggest that physiotherapy leaders in Sweden contribute to a modest degree to establishing a culture conducive to implementation of an evidence-based physiotherapy practice.
\end{abstract}

\section{Keywords}

Leadership, Culture, Evidence-Based Practice, Implementation, Physiotherapy

\section{Introduction}

The emergence of evidence-based medicine (EBM) and its broader application as evi- 
dence-based practice (EBP) has highlighted the need for wider use of research in many practice settings, including physiotherapy. EBP is typically described in terms of integrating three forms of knowledge: knowledge derived from research, knowledge based on practitioners' experience and the patient's values and priorities (Sackett, Rosenberg, Gray, Haynes, \& Richardson, 1996). Two conceptualizations of EBP are commonly described in the literature: EBP as a critical appraisal (or decision-making) process and EBP as specific evidence-based practices (Midgley, 2009; Olsson, 2007). EBP was originally conceptualized as a process comprised of five steps: formulate an answerable question based on the patient's problems; track down the best relevant evidence; critically appraise its validity and usefulness; integrate this appraisal with clinical practice and patients' values and preferences; and evaluate the outcomes. The second conceptualization of EBP refers to specific practices, e.g. methods, interventions and programmes, the effectiveness of which is supported by empirical research; these practices may be recommended in guidelines produced by government agencies and professional organizations.

Research in physiotherapy has increased rapidly over the last decade, yet studies have shown that many practice decisions continue to be based on knowledge obtained during initial physiotherapy education and/or personal experience, rather than findings from research (Bridges, Bierema, \& Valentine, 2007; Filbay, Hayes, \& Holland, 2012; Heiwe et al., 2011).

Many barriers to achieving a more EBP in physiotherapy have been identified; most are broadly similar to those pertaining to other professions in health care, including time restrictions, limited access to research studies, poor confidence in skills to identify and critically appraise research, inadequate support from colleagues and managers as well as a paucity of research in some areas of physiotherapy (Barnard \& Wiles, 2001; Baxter, 2003; Dannapfel, Peolsson, \& Nilsen, 2013; Fruth et al., 2010; Grimmer-Somers, Lekkas, Nyland, Young, \& Kumar, 2007; Hannes, Staes, Goedhuys, \& Aertgeerts, 2009; Herbert, Sherrington, Maher, \& Moseley, 2001; Iles \& Davidson, 2006; Jette et al., 2003; Kamwendo, 2002; Nilsagård \& Lohse, 2010; Palfreyman, Tod, \& Doyle, 2003; Stevenson, Phil, Lewis, \& Hay, 2004). Barriers to the implementation of EBP have predominantly been sought at the individual provider level, yet there is increasing recognition in implementation science of the relevance of the organizational context, i.e. influences beyond the individual level (Dannapfel et al., 2013; Durlak \& DuPre, 2008; Fixsen, Naoom, Blasé, Friedman, \& Wallace, 2005; Greenhalgh, Robert, Macfarlane, Bate, \& Kyriakidou, 2004; Nilsen, 2015).

Leadership has been recognized to have an important contextual influence on the implementation of EBP in various clinical settings (Aarons, Ehrhart, \& Farahnak, 2014; Damschroder et al., 2009; Gurses et al., 2010; Nutley, Walter, \& Davies, 2007; RycroftMalone \& Bucknall, 2010). There is no universally agreed upon definition of leadership but many conceptualizations reflect the assumption that leadership involves a process of one person exerting intentional influence over another person or group in order to achieve a certain outcome in a group or organization (Gill, 2011; Yukl, 2006). Leader- 
ship commitment and active interest have been shown to positively affect the effectiveness of implementation (Helfrich et al., 2007; Stetler, Damschroder, Helfrich, \& Hagedorn, 2011; Taylor et al., 2011).

Leaders have a crucial role in shaping the culture of an organization and groups with a shared history within an organization (Gill, 2011; Schein, 2010). Culture has been defined as the shared values (important and lasting ideals and preferences for certain behaviours) norms (beliefs about acceptable behaviours) and assumptions (unspoken beliefs and expectations) among members of an organization or group (Bang, 2009). Schein (2010) emphasizes the importance of unconscious taken-for-granted assumptions. An organizational culture comprises multiple subcultures, typically of a professional, departmental or geographical nature (Gill, 2011). Many of the individual barriers to implementation of EBP, e.g. lack of time to search for and appraise research and insufficient support for this process, have been linked to cultural issues, suggesting that culture is an important inhibiting factor for implementing EBP (Nutley et al., 2007; Sibbald, Wathen, \& Kothari, 2016; Williams, Periilo, \& Brown, 2015).

The relevance of leadership and culture in organizations has increasingly been acknowledged in implementation science (Aarons et al., 2014; Dannapfel et al., 2013) but we have not been able to find any empirical research on how managers in health care can influence the organizational or professional culture in achieving more evidencebased physiotherapy practice. There is also a paucity of studies on the relationship between culture and leadership/management in the broader implementation science literature (Reichenpfader, Carlfjord, \& Nilsen, 2015). In recognition of the potential importance of this knowledge gap, this study explored how physiotherapy leaders in Sweden influence the culture for implementation of EBP in physiotherapy. We applied a framework developed by Schein (2010) that identifies a number of mechanisms by which leaders can influence the culture of an organization and/or groups within an organization.

\section{Theoretical Framework}

\section{Influence of Leadership on Organizational Culture}

This study applied Schein's (2010) work on embedding mechanisms, which leaders can use to influence the culture of an organization and/or groups within an organization, to achieve a more informed practice within physiotherapy. Schein posits that leaders can impose their own values, norms and assumptions on others using a number of primary and secondary embedding mechanisms (Table 1). Leaders have six primary mechanisms available to them to influence others on how to perceive, think, feel and behave based on their own convictions. These mechanisms interact and reinforce each other if the leader's own beliefs, values and assumptions are consistent (Schein, 2010). In terms of EBP, the primary embedding mechanisms can be applied by leaders to communicate a desired message, e.g. a positive vision for achieving EBP in physiotherapy. Alternatively, the embedding mechanisms might signify that EBP issues are not important for the profession and/or the health care organization (Aarons et al., 2014). The six 
Table 1. Embedding mechanisms for leadership influence on the culture of an organization and/or groups within an organization (Schein, 2010).

Description

Primary embedding mechanisms

Paying attention to, measuring and controlling on a regular basis

Reaction to critical incidents and crises

Allocation of resources

Deliberate role modelling, teaching and coaching

Allocation of rewards and status

Recruitment, selection, promotion and excommunication

\section{Secondary embedding mechanisms}

Organizational design and structure

Organizational systems and procedures

Rites and rituals of the organization

Design of physical space, facades and buildings

Stories about important events and people

Formal statements of organizational philosophy, creeds and charters
Leaders communicate values, norms and assumptions to followers based on what and where they place their attention, what they measure and attempt to control on a regular basis

Leader's responses to critical situations reveal their values, norms and underlying assumptions; crises tend to expose people's deeper values

The manner in which budget resources are allocated and related to goal setting and strategy formulation reveal leaders' values, norms and assumptions

Personal examples of leaders can show their values, norms and assumptions, thus sending messages to followers, particularly if such actions are ethical and consistent

Leaders communicate their values, norms and assumptions to followers through consistency with the status system, including rewards and promotion

Leaders communicate their values, norms and assumptions by means of how they select, retain and promote people in an organization and/or a group

The way leaders design and structure organizations reflect their assumptions regarding how goals can best be achieved; however, the design and structure rarely provides an accurate basis for embedding leaders' assumptions because the design and structure may be interpreted by employees in many different ways

Recurrent routines, procedures, reports, forms and other tasks are visible aspects of an organization; they lend structure and predictability to work and provide opportunities for leaders to reinforce their assumptions

Rites and rituals are symbolic ways to formalize certain assumptions; they can be important reinforcers of cultural assumptions if those assumptions are made clear by the primary embedding mechanisms

Physical design encompasses all the visual features of an organization, which can reinforce the leaders' messages if they are managed to accomplish this

Stories, legends or myths reinforce assumptions and teach assumptions to newcomers

Formal statements are attempts by leaders to state explicitly what their values, norms and assumptions are

secondary mechanisms are reinforcement mechanisms that support and perpetuate the culture provided they are consistent with the primary mechanisms (Schein, 2010). 


\section{Methods}

\subsection{Study Setting}

This study took place in Sweden. Health care in Sweden is publicly funded, i.e. residents are insured by the state with equal access for the entire population and fees regulated by law. The provision of health care services is the responsibility of the 21 county councils in Sweden. Physiotherapists in Sweden are usually employed by county councils (public sector) or occupational health care organizations (private or public sector). Patients in Sweden do not need a referral from a physician to consult a physiotherapist and are free to choose a physiotherapist from the private or public sector.

\subsection{Study Design}

A qualitative approach with interviews was used. The purpose of a qualitative interview is to understand the participant's point of view and to uncover their lived experience prior to scientific explanations. An interview is a professional conversation where two people converse about a topic of mutual interest and knowledge is constructed during the interaction between the interviewer and the interviewee (Kvale \& Brinkmann, 2008).

Nine physiotherapists in management positions in a clinic employing physiotherapists were interviewed for the study. They represented five different county councils in Sweden. They are referred to as leaders in the text because they all had a mandate and the opportunity to influence how EBP-relevant issues are prioritized in the clinics.

The leaders were recruited through an e-mail that briefly described the study. The e-mail request was sent to 30 managers who were identified through different county council websites with contact information for clinics that employed physiotherapists. Variety was sought according to the clinical setting. The e-mail was sent to hospitals, primary care and private clinics. The managers were also asked if they knew other managers who would be interested in participating in the study. Two of the participants were recruited via such a recommendation from a participating manager. All managers who answered positively were included in the study. The objective was to recruit participants who represented a broad spectrum of experiences and contexts to strengthen the validity of the study (Patton, 2002).

\subsection{Participants}

Table 2 provides data on the participants in the study. The leaders held somewhat different positions, but they were all middle managers in their respective county councils. Their clinics included physiotherapists, occupational therapists and assistant nurses. Several of the leaders were members of steering groups or boards involving managers from different clinics, including other professional groups.

\subsection{Data Collection}

An interview guide was developed by the authors of the study and was scrutinized by two other researchers with a background in nursing and psychology. The questions explored the influence of the leaders on the culture for implementation of EBP in physio- 
Table 2. Sociodemographic data of the participants $(N=9)$.

\begin{tabular}{lc}
\hline Characteristics & Value \\
\hline Demographics & $6(67)$ \\
Sex, $n(\%)$ female & $41(11) ; 32-64$ \\
Age (years), mean (SD); range & \\
Practice and education & $13(9.2) ; 11$ months to 15 \\
Years of practice as manager, mean (SD); range & $1(11)$ \\
PhD degree, $n(\%)$ & $1(11)$ \\
Master degree, $n(\%)$ & $7(78)$ \\
Bachelor degree, $n(\%)$ & \\
Location of the unit $(N=9)$ & $4(36)$ \\
Rural setting, $n(\%)$ & $7(64)$ \\
Urban setting, $n(\%)$ & \\
Type of unit $(N=9)$ & $4(44)$ \\
University hospital, $n(\%)$ & $4(44)$ \\
County hospital, $n(\%)$ & $1(11)$ \\
Primary care, $n(\%)$ &
\end{tabular}

therapy and were inspired by the six embedding mechanisms in Schein's (2010) framework.

The interview topics included EBP-related activities that involved physiotherapists in the clinic (e.g. participation in courses or research projects relevant to EBP); leaders' attitudes to role modelling, facilitation of and support for EBP issues; leaders' perceived support for EBP issues from higher management levels in the county council; perceived competencies relevant to EBP in the clinic and the wider county council; how resources are allocated for EBP activities, how they measure and follow-up activities and use of EBP (also if the managers are followed up on their work with EBP in their clinic); how leaders regard EBP in recruitment and promotion.

Interviews were conducted from June 2014 to January 2015. The interviews were conducted during regular working hours at the manager's office and lasted between 50 and 70 minutes, and were recorded with a dictaphone. The participants were informed of the confidentiality of their contribution, that participation was voluntary and that they could withdraw at any time during the interview. The first author of this study conducted the interviews.

\subsection{Data Analysis}

The interview data were analysed using direct content analysis in accordance with Hsieh and Shannon (2005). Content analysis is a technique for analysing texts based on empirical data with an explorative and descriptive character. The use of a deductive category application can help to predict variables of interest and the relationships between variables (Hsieh \& Shannon, 2005). A directed approach in content analysis is 
guided by a structured process with the point of departure for coding in an existing theory or previous research (Hsieh \& Shannon, 2005), in this case Schein's (2010) embedding mechanisms framework, to analyse how leaders can influence the culture of an organization.

As a first step, both authors read all transcripts to obtain an understanding of the whole. The transcripts were then coded by the authors separately, using a directed content analysis that included a structured analysis process to code and categorize the data using Schein's embedding primary and secondary mechanisms as a framework (see Section 2). The framework was used to determine the initial coding and relationships between the codes. Data that could not be coded or identified in relation to Schein's framework in the first step were analysed later to determine if the data represented a new category or a subcategory of an existing category (Hsieh \& Shannon, 2005).

In the next stage, the authors discussed the interpretation of the data in relation to Schein's framework and compared their coding. The discussions continued until no inconsistencies existed and a shared understanding was reached to prevent researcher bias and strengthen the internal validity (Patton, 2002). Representative quotations were identified to report the findings. The quotations were then translated from Swedish to English by the authors.

\section{Results}

We identified a number of mechanisms by which leaders could influence the culture of an organization and/or groups within an organization. The mechanisms of paying attention to, measuring and controlling on a regular basis as well as deliberate role modelling, teaching and coaching did have some relevance. However, to a large extent, EBP issues seemed to depend on committed individuals, often younger physiotherapists, who were interested in research.

The results are presented in accordance with Schein's embedding mechanisms. Findings on each of the six primary mechanisms are presented; the results pertaining to the secondary mechanisms are presented together as few of these reinforcement mechanisms were relevant.

\subsection{Paying Attention to, Measuring and Controlling on a Regular Basis}

The leaders' descriptions of the extent to which EBP-related activities and issues are paid attention to, measured and controlled suggested that this embedding mechanism contributes towards creating a more EBP-informed culture. The leaders observed that there are increasing demands that physiotherapy and health care in general should be underpinned by research and for decisions to be based on evidence of their effectiveness, which means that EBP issues cannot be ignored. In some of the county councils, information about EBP issues in the organization is reported continuously to the county councils' political board, which has responsibility for health care. The boards in these county councils are interested in following how the organization is working towards the political goals for an EBP. 
The leaders highlighted the importance of discussing and planning for EBP-related activities with physiotherapists in the clinics. They commented that a great deal of emphasis was put on using guidelines produced by the National Board of Health and Welfare, although the amount of attention given to the guidelines seemed to vary among the clinics. "We have a lot of discussions regarding EBP and we work to implement national guidelines where such are available. Right now I'm involved in a stroke process, covering all the steps in stroke care in the hospital." (Manager 1, female, 54 years). Another leader said, "I believe that guidelines have been implemented for quite some time here, but it was not until mid-2012 that we [physiotherapists] stressed that we need to be involved in all processes that are relevant to our profession." (Manager 2, female, 36 years).

The leaders mentioned that they had frequent discussions on EBP issues in meetings with higher-level managers in the county councils. However, in relation to budgetary matters or "production" of care, there was less attention paid to EBP issues. The discussions at this level did not concern specific research findings but rather dealt with broader issues related to current EBP-related activities in the clinics and the means by which clinics could develop a more evidence-based physiotherapy practice. "Considering the [management] level above me, the time we talk about research and development is limited in relation to other topics. The importance [of research] has been emphasized by inviting the research and development coordinator [to meetings at the higher management level]. She makes sure that we address research issues. However, we [the clinic] are not being followed up on this, but we do it ourselves to be able to report data in the yearly report." (Manager 3, female, 64 years).

The leaders perceived that a great deal of attention was being paid to EBP issues from the higher management level. However, they noted that there were few systematic efforts or structures to conduct follow-ups or evaluations that might contribute to a more EBP-informed culture. Instead, the county councils' measurement and control efforts were predominantly directed towards financial and production objectives, rather than EBP issues. "There is limited focus on it [research or EBP]. The questions usually concern budget and production issues. As long as I have been here, no one has asked me about it [use of research], but there are two levels of managers above me. I know that there are expectations about development, becoming more effective and EBP." (Manager 4 , female, 35 years).

\subsection{Reaction to Critical Incidents and Crises}

This embedding mechanism largely lacked relevance with regard to fostering a more EBP-informed culture. The leaders recognized challenges to obtain support for EBPrelated activities from higher management levels in times of organizational stress in the clinics or in the county council as a whole. They noted that their managers did not encourage change efforts in times of cut backs or high staff turnover at the clinics. "The focus and demand on productivity and related measures in the clinic from my manager has increased. This makes it more difficult to work with EBP in the clinic. The eco- 
nomic focus is dangerous and can be 'traumatic' for subordinates when they become aware of the economic restrictions. We need a [better] balance, but I have not had much support in this matter." (Manager 5, female, 43 years). Another leader remarked, "It is not possible to say that we should invest in research if we don't get any extra resources for this in the clinics. We can't do everything within the [current] budget framework; it's not possible" (Manager 6, female, 55 years). Strategies in terms of long-term planning for involvement in research projects, reading scientific articles and other activities related to EBP were also affected negatively, particularly in times of organizational and clinical stress due to lack of personnel resources or finances.

\subsection{Allocation of Resources}

The leaders believed that resources earmarked for EBP-related activities were insufficient. They remarked that financial and budgetary issues were prioritized by managers at the higher levels in the county councils. This meant that the managers' espoused values and norms concerning EBP did not always match their financial decisions with regard to EBP issues. "There is a lot of talk that everyone should write documents [regarding EBP]. But they [the documents] are not supported by the economy, so all these good research strategies that have been articulated do not have the [financial] backing in the budget." (Manager 6, female, 55 years).

Resources were also described in terms of EBP-relevant competencies, i.e. more intangible resources. Training for improved EBP skills and time set aside for knowledge exchange on research matters in the clinics were two ways of providing resources to benefit a more EBP-informed culture. "Every other Thursday we have one hour planned for internal education. It can be a subordinate who has attended a course passing that knowledge on to colleagues. The time is also used to update on, for instance, rehabilitation programmes or other issues of importance to change or improve [our clinical practice]." (Manager 2, female, 36 years). Another leader noted, "In the beginning when I allocated resources for development work it was not always popular. After all, time is limited and patient work is always most important, but it is important to hang in there. It is a lot about changing attitudes. No one is really questioning it [the importance of EBP].” (Manager 5, female, 43 years).

\subsection{Deliberate Role Modelling, Teaching and Coaching}

Role modelling, teaching and coaching were applied as embedding mechanisms to achieve a more EBP-informed culture. Many of the leaders took their role as EBP leaders seriously and were anxious to support various EBP-related activities despite resource constraints. They stressed that they as leaders need to be knowledgeable on EBP issues to be able to supervise and support their subordinates in their efforts. "That's part of why you take on a manager assignment [to work with research and development]. In my role as a manager this is really important, not least because we are part of a university hospital, which defines us. This requires that you have plans and contribute to the integration of EBP." (Manager 7, male, 44 years). It was also stated, "I believe 
that it is important [to work with EBP issues] and I encourage that research and development is on the agenda. It should not be something that is hidden under the table." (Manager 1, female, 54 years).

EBP-related knowledge and expertise differed among the leaders, influencing their ability to function as EBP leaders. Some had experience from research projects, initiatives aimed at implementing EBP and various change management projects, whereas others had limited research experience and felt considerably less secure about their role as role models in terms of EBP issues. 'It's an area [EBP] where I don't have so much training. Currently the dissemination of implementation knowledge mostly occurs through sharing experiences from larger implementation projects among colleagues. There is no systematic approach to dissemination, which I believe is a hindrance." (Manager 7, male, 44 years).

The leaders also had different experiences concerning support from their managers (at higher county council level) and the wider county council organization. "We have access to research and development support, but the top management can't do much more than try to facilitate this through sending clear messages that physiotherapy must work with development. It makes the discussions easier in the clinics when the message is that you must find time for this [EBP issues]. Such signals should not to be underestimated." (Manager 8, male, 42 years). Another comment was, "I can use our research and development unit and hire an organizational developer for a group or a project. That provides support during the change process and also helps with the evaluation." (Manager 2, female, 36 years).

\subsection{Allocation of Rewards and Status}

The leaders described various means by which EBP expertise was valued. Most leaders created a special status for physiotherapists with more extensive education, training or continuing professional education. "We have a salary increase after finishing a Master's degree; we make room for that in the budget. I think that this is important; it's a long-term strategy and that's why it should be planned for in the budget." (Manager 5, female, 43 years). It was also noted, "We are generous with continuing professional education and let our subordinates be involved in research projects. We also let them have spare days to be able to read to do a Bachelor or Master thesis." (Manager 6, female, 55 years). Another way to allocate rewards was described by one of the leaders, "One reward is to get the opportunity to try a project of one's own in the clinic; it can be a small or a large project. I know that they (subordinates) appreciate this." (Manager 9, female, 53 years).

Some of the leaders had subordinates who are $\mathrm{PhD}$ students, although they complained about the difficulties of retaining them in the clinic after they get their $\mathrm{PhD}$ as they are often employed at universities. Retaining physiotherapists with high levels of research competence was difficult. "Our $\mathrm{R} \& \mathrm{D}$ coordinator talks to all $\mathrm{PhD}$ candidates about what we can do to make them stay in the clinic and discuss their future plans. Many are disappointed when they come back and believe that they should get a new 
position, which is why this talk is so important. If the research [they have done as $\mathrm{PhD}$ students] is in line with what the clinic does, they might be able to conduct further research in the clinic." (Manager 3, female, 64 years).

Some leaders reported that they take EBP competencies and involvement in EBP-related issues into account in their staff appraisals. "You are to evaluate what you do and be updated in what is going on [in research]. We talk about this in the appraisals and it is also related to our criteria for determining the salary." (Manager 1, female, 54 years).

The leaders mentioned that clinics that conduct research and pursue EBP-related activities were recognized by the higher management levels. "You get attention concerning how much research is conducted. We measure it [the research activity]. However, my experience is that even if we conduct a great deal of research, there is only a small part of it being implemented." (Manager 8, male, 44 years). Another leader said, "Since I did my Master's thesis, I have been invited to talk about it in many different forums. It has been busy and I've had a really good response, which is really fun. I really get support and this is also emphasized when I talk to my manager about salary and my performance appraisal." (Manager 1, female, 54 years).

\subsection{Recruitment, Selection, Promotion and Excommunication}

The leaders described the importance of building capacity for EBP by appointing some physiotherapists in a special role with responsibility for EBP issues in the clinic. They were often highly motivated to keep up to date on physiotherapy research and support implementation of EBP in the clinic. "I have appointed a person to the task of working with development in the clinic. She noticed that our implementation strategies are vague and unclear. We now work to upgrade and change our implementation strategy." (Manager 3, female, 64 years). Another leader observed, "It has been a long journey in the 10 years that I have worked here. In the last 6years we have started to work in a more structured way [with EBP issues]. We have physiotherapists who have played a huge part in this during their Master's education. They have really pushed this [EBP issues] forward." (Manager 5, female, 43 years).

The leaders also emphasized the importance of recruiting new young physiotherapists because they are often competent in EBP issues. "I find that the younger physiotherapists are more engaged (in EBP) and I get the feeling that older physiotherapists are more, like, 'I want to work with my patients, why can't I just do that."' (Manager 3, female, 54 years). On the down side, it might take longer for a newrecruit to be highly productive than for those who have worked for many years in physiotherapy.

\subsection{Secondary Embedding Mechanisms}

Few of the secondary embedding mechanisms described by Schein (2010) had much relevance with regard to influencing or reinforcing an EBP-informed culture. The organizational design, structure, systems and procedures did not appear to be particularly conducive to EBP and the leaders did not mention any specific rites or rituals in their organizations that were relevant to EBP issues. Furthermore, there were no obvious 
links between EBP issues and the design of the physical space, facades and buildings. Also, the leaders did not relate any stories about important events and people that seemed to be related to EBP-related activities.

The leaders could, however, provide a few examples of formal statements concerning EBP issues. The county councils report on various EBP-related activities in their annual reports but the extent to which this is done varied greatly. Scientific publications and the number of staff with $\mathrm{PhD}$ degrees or professor titles are often reported but less focus is placed on what improvements have been achieved or the extent to which research has been integrated into routine practice to improve the clinics' work. "In the Dialogue [a questionnaire that is sent to all managers yearly] that is used for follow-up every year, we report how many improvement projects we have carried out. I think that they also discuss whether these projects have had any impact in the clinic." (Manager 6, female, 55 years).

\section{Discussion}

This study explored how leaders in Swedish health care can contribute to developing a culture that is conducive to implementation of EBP in physiotherapy. We applied a framework developed by Schein (2010) that describes various means by which leaders can communicate their values, norms and assumptions to followers, e.g. members of a profession and/or an organization. This instrument was found to be useful to analyse the potential influence of leaders on the culture for EBP in physiotherapy practice.

Overall, most of the embedding mechanisms seemed to have modest impact on an EBP-informed culture. The mechanism of paying attention to, measuring and controlling on a regular basis had relevance. This is also the most powerful mechanisms according to Schein (2010). Several of the mechanisms were not used consistently. For example, when the clinic was under stress, there was less emphasis on EBP-related activities such as setting aside time for knowledge exchange, involvement in research or building capacity for EBP by appointing personnel, time or financial resources. Some of the leaders interviewed stated that EBP had long been on the agenda and that there was a long-term strategy to achieve a more evidence-based physiotherapy practice. According to Schein (2010), it is not the intensity of the attention but the consistency that can yield cultural changes. He describes this kind of long-term "paying attention to" strategy as a powerful way to communicate what is valued in an organization. Influencing the culture is a complex, time-consuming learning process, which is not only influenced by leaders at all levels but by all members in the organization.

To some extent, the goals of EBP might be seen as a long-term ambition that clashes with the short-term realities of everyday tasks and obligations in physiotherapy practice and other fields of work. EBP involves many learning challenges for health care practitioners. To practice EBP, they must be able to search the research literature, critically appraise studies and integrate research into clinical decisions. Implementation of EBP also occurs through the adoption and use of various diagnosis, prognosis and treatment methods (i.e. evidence-based practices). Learning new practices might require training 
as well as ongoing supervision, monitoring and consultation. There is an obvious tension between time required for handling the daily flow of events in physiotherapy practice and the time needed for learning to realize the ideals of EBP. A difficulty in establishing a balance between the short and long term is that the benefits of learning activities tend to be more remote in time and less reliable than the more easily calculated value of measures to boost day-to-day work processes and production (Nilsen, Nordström, \& Ellström, 2011).

Deliberate role modelling, teaching and coaching was another of Schein's (2010) mechanisms that had relevance in our study. The leaders recognized the importance of expressing and trying to convey positive attitudes to EBP to make research use a natural and accepted way of working with patients in the clinics. Previous research has shown that physiotherapists are generally positive towards EBP (Barnard \& Wiles, 2001; Bernhardsson, Johansson, Nilsen, Öberg, \& Larsson, 2014; Grimmer-Somers et al., 2007; Heiwe et al., 2011, Iles \& Davidson, 2006; Kamwendo, 2002; Nilsagård \& Lohse, 2010; Stevenson et al., 2004). Positive attitudes to research have been identified as a key factor associated with a high degree of research use in physiotherapy practice (Dannapfel et al., 2013; Iles \& Davidson, 2006; Jette et al., 2003).

Members of an organization whose commitment is based on a genuine interest (i.e. based on more intrinsic motivation) to perform a certain behaviour, rather than a felt need or pressure, are more likely to champion and promote the value of the behaviour to colleagues (Dannapfel et al., 2013; Herscovitch \& Meyer, 2002).

Leaders in our study often appointed formal or informal EBP experts in the clinics, i.e. physiotherapists who kept up to date with and informed colleagues about the latest physiotherapy research findings. These physiotherapists usually took a personal interest in research and development issues. However, delegating much of the responsibility for implementation of EBP to individual physiotherapists means that EBP issues become less of a collective or leadership responsibility. These dedicated individuals effectively functioned as champions for EBP as they were expected to facilitate and promote EBP in the clinics. Rogers' (2005) Theory of Diffusion highlights the importance of intermediary actors such as opinion leaders and change agents for successful adoption and implementation of innovations. Similar roles are described in numerous frameworks and models applied in implementation science (Nilsen, 2015). Although having champions of EBP has been shown to be important for successful implementation of EBP in various settings (Aarons, Sommerfeld, \& Willging, 2011; Berta et al., 2005; Greenhalgh et al., 2004; Simpson, 2002), there are also disadvantages in becoming too dependent on individuals because sustainability of EBP may be compromised if these individuals retire or take up other job opportunities (Damschroder et al., 2009; Ridelberg \& Nilsen, 2015).

The EBP experts were often younger physiotherapists who took a stronger interest in research than older colleagues who may not have studied EBP issues as part of their basic education. This finding suggests that a generational shift within physiotherapy might be conducive to developing a more EBP-informed culture in the future. From a 
more long-term perspective, the focus on implementing EBP is a relatively recent phenomenon. EBM was first described in 1992 and the earliest studies investigating EBP in physiotherapy emerged in the late 1990s. It has been suggested that implementation science and research on education and training structures and strategies for EBP are all in their early stages of development (Soydan \& Palinkas, 2014).

Implementation of EBP implies change; preconceived notions of what is the best practice concerning diagnosis, prognosis and treatment methods might be challenged by new research findings. Physiotherapy has seen an enormous increase in the volume and accessibility of high-quality clinical research, to the extent that it is difficult for many to keep pace with the latest research advances. In many ways, change in health care has become continuous due to the steady pace of new research findings. There is substantial pressure for physiotherapists to adopt EBP (Iles \& Davidson, 2006).

The leaders in our study perceived some support for EBP from the higher management levels in the county councils. However, many mentioned that there were few strategic or systematic efforts or discussions concerning EBP among managers at the higher levels. It was obvious that financial, budgetary and production matters took precedence over EBP-related issues at the higher management levels, with regard to what was paid attention to, measured and controlled. Furthermore, embedding mechanisms such as allocation of resources and reaction to critical incidents and organizational crises did not contribute to creating a more EBP-informed culture. Leaders in this study observed that implementation of EBP suffered when the organization was under stress. The organizations did not seem to have a systematic way to simultaneously manage the clinics' "production demands" and developing and pursuing EBP activities.

The leaders who were interviewed are situated and operate at the meso level of the county councils. The culture at this level might differ to some extent from the culture at the micro level, i.e. the workgroups, including different health care practitioners. Martin (2002) argues that organizational cultures can be integrated; differentiated or fragmented; this is also highlighted by Schein. Researchers have increasingly argued that an organization's culture really is an amalgamation of many cultures. A subculture has been defined as a subset of an organization's members who interact regularly with one another, identify themselves as a distinct group, share a set of problems and routinely take action on the basis of collective understandings unique to the group (Morgan \& Ogbonna, 2008). The existence of professional subcultures in health care has been demonstrated (Horsburgh et al. 2006; Lok, Rhodes, \& Westwood, 2011), including studies on implementation of various reforms and methods (Callen \& Lee, 2009; Martinussen \& Magnussen, 2011). There are likely different EBP subcultures at different hierarchical levels of health care organizations although this has not been studied (to the best of our knowledge). We believe it is important to account for the different system levels of influence on EBP to understand the conditions for creating an EBP culture.

Some limitations of this study should be noted when interpreting its findings. All qualitative research is limited regarding its generalizability to other settings and populations. The leaders interviewed for our study were managers at the middle level of the 
county councils in which they were employed. Managers are not necessarily leaders, but the roles of leaders and managers usually overlap (Yukl, 2006). Research on leadership in relation to implementation of EBP has usually conceptualized leadership as supervisory or managerial leadership (Cummings et al., 2010; Damschroder et al., 2011; Forsman et al., 2012; Gifford Davies, Edwards, Griffin, \& Lybanon, 2007; Reichenpfader et al., 2015). However, we specifically sought to include managers whose characteristics were consistent with established definitions of leaders. For example, the participants were all able to make decisions regarding the prioritization of EBP-relevant issues and determine which EBP activities should be carried out in the clinics.

\section{Conclusion}

Applying a framework that describes a number of mechanisms by which leaders can influence the culture of an organization and groups within the organization, this study explores how physiotherapy leaders in Sweden influence the culture for implementation of EBP in physiotherapy practice. The mechanisms of paying attention to, measuring and controlling on a regular basis as well as deliberate role modelling, teaching and coaching did have relevance. EBP issues seemed to depend on committed individuals, i.e. managers, physiotherapists with a special interest in EBP or younger physiotherapists who were interested in research. The findings suggest that leaders' paying attention to, measuring and controlling on a regular basis is the most important mechanism for establishing a culture conducive to implementation of an evidence-based physiotherapy practice.

\section{References}

Aarons, G. A., Ehrhart, M., \& Farahnak, L. R. (2014). The Implementation Leadership Scale (ILS): Development of a Brief Measure of Unit Level Implementation Leadership. Implementation Science, 9, 45. http://dx.doi.org/10.1186/1748-5908-9-45

Aarons, G. A., Sommerfeld, D. H., \&Willging, C. E. (2011). The Soft Underbelly of System Change: The Role of Leadership and Organizational Climate in Turnover during Statewide Behavioral Health Reform. Psychological Services, 8, 269-281. http://dx.doi.org/10.1037/a0026196

Bang, H. (2009). Organisationskultur. Malmö: Studentlitteratur.

Barnard, S., \& Wiles, R. (2001). Evidence-Based Physiotherapy: Physiotherapists' Attitudes and Experiences in the Wessex Area. Physiotherapy, 87, 115-124.

http://dx.doi.org/10.1016/S0031-9406(05)61078-4

Baxter, D. (2003). Editorial: The End of Evidence-Based Practice? Physical Therapy Reviews, 8, 34. http://dx.doi.org/10.1179/108331903225001561

Bernhardsson, S., Johansson, K., Nilsen, P., Öberg, B., \& Larsson, M. E. (2014). Determinants of Guideline Use in Primary Care Physical Therapy: A Cross-Sectional Survey of Attitudes, Knowledge, and Behavior. Physical Therapy, 94, 343-345.

http://dx.doi.org/10.2522/ptj.20130147

Berta, W., Teare, G. F., Gilbart, E., Ginsburg, L. S., Lemieux-Charles, L., Davis, D. et al. (2005). The Contingencies of Organizational Learning in Long-Term Care: Factors That Affect Innovation Adoption. Health Care Management Review, 30, 282-292. 
http://dx.doi.org/10.1097/00004010-200510000-00002

Bridges, P. H., Bierema, L. L., \& Valentine, T. (2007). The Propensity to Adopt Evidence-Based Practice among Physical Therapists. BMC Health Services Research, 7, 103.

http://dx.doi.org/10.1186/1472-6963-7-103

Callen, B., \& Lee, J. (2009). Ready for the World: Preparing Nursing Students for Tomorrow. Journal of Professional Nursing, 25, 292-298. http://dx.doi.org/10.1016/j.profnurs.2009.01.021

Cummings, G. G., MacGregor, T., Davey, M.,Lee, H., Wong, C. A., Lo, E. et al. (2010). Leadership Styles and Outcome Patterns for the Nursing Workforce and Work Environment: A Systematic Review. International Journal of Nursing Studies, 47, 363-385. http://dx.doi.org/10.1016/j.ijnurstu.2009.08.006

Damschroder, L. J., Aron, D. C., Keith, R. E., Kirsh, S. R., Alexander, J. A., \& Lowery, J. C. (2009). Fostering Implementation of Health Services Research Findings into Practice: A Consolidated Framework for Advancing Implementation Science. Implementation Science, 4, 50.

http://dx.doi.org/10.1186/1748-5908-4-50

Damschroder, L. J., Goodrich, D. E., Robinson, C. H., Fletcher, C. E., \& Lowery, J. C. (2011). A Systematic Exploration of Differences in Contextual Factors Related to Implementing the MOVE! Weight Management Program in VA: A Mixed Methods Study. BMC Health Services Research, 11, 248. http://dx.doi.org/10.1186/1472-6963-11-248

Dannapfel, P., Peolsson, A., \& Nilsen, P. (2013). What Supports Physiotherapists' Use of Research in Clinical Practice? A Qualitative Study. Implementation Science, 8, 31. http://dx.doi.org/10.1186/1748-5908-8-31

Durlak, J. A., \& DuPre, E. P. (2008). Implementation Matters: A Review of Research on the Influence of Implementation on Program Outcomes and the Factors Affecting Implementation. American Journal of Community Psychology, 41, 237-350.

http://dx.doi.org/10.1007/s10464-008-9165-0

Filbay, S. R., Hayes, K., \& Holland, A. E. (2012). Physiotherapy for Patients Following Coronary Artery Bypass Graft (CABG) Surgery: Limited Uptake of Evidence into Practice. Physiotherapy Theory and Practice, 28, 178-287. http://dx.doi.org/10.3109/09593985.2011.582231

Fixsen, D. L., Naoom, S. F., Blasé, K. A., Friedman, R. M., \& Wallace, F. (2005). Implementation Research: A Synthesis of the Literature. Tampa, FL: University of South Florida, Louis de la Parte Florida Mental Health Institute, The National Implementation Research Network.

Fruth, S. J., van Veld, R. D., Despos, C. A., Martin, R. D., Hecker, A., \& Sincroft, E. E. (2010). The Influence of a Topic-Specific Research-Based Presentation on Therapists' Beliefs and Practices Regarding Evidence-Based Practice. Physiotherapy Theory and Practice, 26, 537-557. http://dx.doi.org/10.3109/09593980903585034

Gifford, W., Davies, B., Edwards, N., Griffin, P., \& Lybanon, V. (2007). Managerial Leadership for Nurses' Use of Research Evidence: An Integrative Review of the Literature. Worldviews on Evidence-Based Nursing, 4, 126-145. http://dx.doi.org/10.1111/j.1741-6787.2007.00095.x

Gill, R. (2011). Theory and Practice of Leadership. London: Sage Publications.

Greenhalgh, T., Robert, G., Macfarlane, F., Bate, P., \& Kyriakidou, O. (2004). Diffusion of Innovations in Service Organizations: Systematic Review and Recommendations. The Milbank Quarterly, 82, 581-629. http://dx.doi.org/10.1111/j.0887-378X.2004.00325.x

Grimmer-Somers, K., Lekkas, P., Nyland, L., Young, A., \& Kumar, S. (2007). Perspectives on Research Evidence and Clinical Practice: A Survey of Australian Physiotherapists. Physiotherapy Research International, 12, 147-161. http://dx.doi.org/10.1002/pri.363

Gurses, A. P., Marsteller, J. A., Ozok, A. A., Xiao, Y., Owens, S., \& Pronovost, P. J. (2010). Using an Interdisciplinary Approach to Identify Factors That Affect Clinicians' Compliance with 
Evidence-Based Guidelines. Critical Care Medicine, 38, S282-S291.

http://dx.doi.org/10.1097/CCM.0b013e3181e69e02

Hannes, K., Staes, F., Goedhuys, J., \& Aertgeerts, B. (2009). Obstacles to the Implementation of Evidence-Based Physiotherapy in Practice: A Focus Group-Based Study in Belgium (Flanders). Physiotherapy Theory and Practice, 25, 476-488.

http://dx.doi.org/10.3109/09593980802661949

Heiwe, S., Nilsson Kajermo, K., Tyni-Lenné, R., Guidetti, S., Samuelsson, M., \& Andersson, I.-L. et al. (2011). Evidence-Based Practice: Attitudes, Knowledge and Behaviour among Allied Health Care Professionals. International Journal for Quality in Health Care, 23, 198-209. http://dx.doi.org/10.1093/intqhc/mzq083

Helfrich, C. D., Weiner, B. J., McKinney, M. M., \& Minasian, L. (2007). Determinants of Implementation Effectiveness: Adapting a Framework for Complex Innovations. Medical Care Research and Review, 64, 279-303. http://dx.doi.org/10.1177/1077558707299887

Herbert, R. D., Sherrington, C., Maher, C., \& Moseley, A. M. (2001). Evidence-Based PracticeImperfect but Necessary. Physiotherapy Theory and Practice, 17, 201-211.

http://dx.doi.org/10.1080/095939801317077650

Herscovitch, L., \& Meyer, J. P. (2002). Commitment to Organizational Change: Extension of a Three-Component Model. Journal of Applied Psychology, 87, 474-487.

http://dx.doi.org/10.1037/0021-9010.87.3.474

Horsburgh, M., Merry, A., Seddon, M., Baker, H., Poole, P., \& Shaw, J. et al. (2006). Educating for Healthcare Quality Improvement in an Interprofessional Learning Environment: A New Zealand Initiative. Journal of Interprofessional Care, 20, 555-557. http://dx.doi.org/10.1080/13561820600890185

Hsieh, H. F., \& Shannon, S. E. (2005). Three Approaches to Qualitative Content Analysis. Qualitative Health Research, 15, 1277-1288. http://dx.doi.org/10.1177/1049732305276687

Iles, R., \& Davidson, M. (2006). Evidence Based Practice: A Survey of Physiotherapists' Current Practice. Physiotherapy Research International, 11, 93-103. http://dx.doi.org/10.1002/pri.328

Jette, D. U., Bacon, K., Batty, C., Carlson, M., Ferland, A., \& Hemingway, R. D. et al. (2003). Evidence-Based Practice: Beliefs, Attitudes, Knowledge, and Behavior of Physical Therapists. Physical Therapy, 83, 786-805.

Kamwendo, K. (2002). What Do Swedish Physiotherapists Feel about Research? A Survey of Perceptions, Attitudes, Intentions and Engagement. Physiotherapy Research International, 7, 2334. http://dx.doi.org/10.1002/pri.238

Kvale, S., \& Brinkmann, S. (2008). Den Kvalitativa Forskningsintervjun. Lund: Studentlitteratur.

Lok, P., Rhodes, J., \& Westwood, B. (2011). The Mediating Role of Organizational Subcultures in Health Care Organizations. Journal of Health Organization and Management, 25, 506-525. http://dx.doi.org/10.1108/14777261111161860

Martinussen, P. E., \& Magnussen, J. (2011). Resisting Market-Inspired Reform in Healthcare: The Role of Professional Subcultures in Medicine. Social Science \& Medicine, 73, 193-200. http://dx.doi.org/10.1016/j.socscimed.2011.04.025

Midgley, N. (2009). Disseminators vs Revisionists: Attitudes to the "Implementation Gap" in Evidence-Based Practice. Journal of Children's Services, 4, 28-38. http://dx.doi.org/10.5042/jcs.2010.0019

Morgan, P. I., \& Ogbonna, E. (2008). Subcultural Dynamics in Transformation: A Multi-Perspective Study of Healthcare Professionals. Human Relations, 61, 39-65.

http://dx.doi.org/10.1177/0018726707085945 
Nilsagård, Y., \& Lohse, G. (2010). Evidence-Based Physiotherapy: A Survey of Knowledge, Behaviour, Attitudes and Prerequisites. Advances in Physiotherapy, 12, 179-186.

http://dx.doi.org/10.3109/14038196.2010.503812

Nilsen, P. (2015). Making Sense of Implementation Theories, Models and Frameworks. Implementation Science, 10, 53. http://dx.doi.org/10.1186/s13012-015-0242-0

Nilsen, P., Nordström, G., \& Ellström, P.-E. (2011). Integrating Research-Based and Practice-Based Knowledge through Workplace Reflection. Journal of Workplace Learning, 24, 403415. http://dx.doi.org/10.1108/13665621211250306

Nutley, S. M., Walter, I., \& Davies, H. T. O. (2007). Using Evidence: How Research Can Inform Public Services. Bristol: The Policy Press.

Olsson, T. M. (2007). Reconstructing Evidence-Based Practice: An Investigation of Three Conceptualisations of EBP. Evidence \& Policy, 3, 271-285. http://dx.doi.org/10.1332/174426407781172153

Palfreyman, S., Tod, A., \& Doyle, J. (2003). Comparing Evidence-Based Practice of Nurses and Physiotherapists. British Journal of Nursing, 12, 246-253.

http://dx.doi.org/10.12968/bjon.2003.12.4.11165

Patton, M. Q. (2002). Qualitative Research and Evaluation Methods. Thousand Oaks, CA: Sage Publications.

Reichenpfader, U., Carlfjord, S., \& Nilsen, P. (2015). Leadership in Evidence-Based Practice: A Systematic Review. Leadership in Health Services, 28, 298-316.

http://dx.doi.org/10.1108/LHS-08-2014-0061

Ridelberg, M., \& Nilsen, P. (2015). Using Surveillance Data to Reduce Health Care-Associated Infection: A Qualitative Study in Sweden. Journal of Infection Prevention, 16, 208-214. http://dx.doi.org/10.1177/1757177415588380

Rogers, E. M. (1993). Diffusion of Innovations (5th ed.). New York: Free Press.

Rycroft-Malone, J., \& Bucknall, T. (2010). Theory, Frameworks, and Models: Laying Down the Groundwork. In J. Rycroft-Malone, \& T. Bucknall (Eds.), Models and Frameworks for Implementing Evidence-Based Practice (pp. 23-50). Chichester: Wiley-Blackwell.

Sackett, D. L., Rosenberg, W. M., Gray, J. A., Haynes, R. B., \& Richardson, W. S. (1996). Evidence-Based Medicine: What It Is and What It Isn't. British Medical Journal, 312, 71. http://dx.doi.org/10.1136/bmj.312.7023.71

Schein, E. H. (2010). Organizational Culture and Leadership (4th ed.). San Francisco, CA: Jossey-Bass.

Sibbald, S. L., Wathen, C. N., \& Kothari, A. (2016). An Empirically Based Model for Knowledge Management in Health Care Organizations. Health Care Management Review, 41, 64-74. http://dx.doi.org/10.1097/HMR.0000000000000046

Simpson, D. D. (2002). A Conceptual Framework for Transferring Research to Practice. Journal of Substance Abuse Treatment, 22, 171-182. http://dx.doi.org/10.1016/S0740-5472(02)00231-3

Soydan, H., \& Palinkas, L. A. (2014). Evidence-Based Practice in Social Work. Abingdon-onThames: Routledge.

Stetler, C. B., Damschroder, L. J., Helfrich, C. D., \& Hagedorn, H. J. (2011). A Guide for Applying a Revised Version of the PARIHS Framework for Implementation. Implementation Science, 6, 99. http://dx.doi.org/10.1186/1748-5908-6-99

Stevenson, K., Phil, M., Lewis, M., \& Hay, E. (2004). Do Physiotherapists' Attitudes Towards Evidence-Based Practice Change as a Result of an Evidence-Based Educational Program? Journal of Evaluation in Clinical Practice, 10, 207-217. http://dx.doi.org/10.1111/j.1365-2753.2003.00479.x 
Taylor, S. L., Dy, S., Foy, R., Hempel, S., McDonald, K. M., \& Ovretveit, J. et al. (2011). What Context Features Might Be Important Determinants of the Effectiveness of Patient Safety Practice Interventions? BMJ Quality and Safety, 20, 611-617.

http://dx.doi.org/10.1136/bmjqs.2010.049379

Williams, B., Perillo, S., \& Brown, T. (2015). What Are the Factors of Organisational Culture in Health Care Settings That Act as Barriers to the Implementation of Evidence-Based Practice? A Scoping Review. Nurse Education Today, 35, e34-e41.

http://dx.doi.org/10.1016/j.nedt.2014.11.012

Yukl, G. (2006). Leadership in Organizations (6th ed.). Upper Saddle River, NJ: Pearson Education.

Submit or recommend next manuscript to SCIRP and we will provide best service for you:

Accepting pre-submission inquiries through Email, Facebook, LinkedIn, Twitter, etc.

A wide selection of journals (inclusive of 9 subjects, more than 200 journals)

Providing 24-hour high-quality service

User-friendly online submission system

Fair and swift peer-review system

Efficient typesetting and proofreading procedure

Display of the result of downloads and visits, as well as the number of cited articles

Maximum dissemination of your research work

Submit your manuscript at: http://papersubmission.scirp.org/ 